\title{
Research Paper: Efficacy of Neurofeedback Training on Reading and Spelling Skills of 8 to 12 Years Old Children With Dyslexia
}

\author{
Shekoofeh Raesi ${ }^{1}$, Hooshang Dadgar ${ }^{2 *}$, Zahra Soleymani ${ }^{3}$, Vahideh Hajjeforoush ${ }^{4}$
}

1. MSc. Student, Department of Speech Therapy, School of Rehabilitation, Tehran University of Medical Sciences, Tehran, Iran.

2. PhD Candidate, Department of Speech Therapy, School of Rehabilitation, Tehran University of Medical Sciences, Tehran, Iran.

3. Assistant Professor, Department of Speech Therapy, School of Rehabilitation, Tehran University of Medical Sciences, Tehran, Iran.

4. MSc., Department of Psychology, Faculty of Psychology and Education, Tehran University of Medical Sciences, Tehran, Iran.

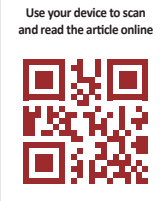

Crtation: Raesi Sh, Dadgar H, Soleymani Z, Hajjeforoush V. Efficacy of Neurofeedback Training on Reading and Spelling Skills of 8 to 12 Years Old Children With Dyslexia. Journal of Modern Rehabilitation. 2016; 10(4):177-184. https://doi. org/10.18869/nirp.jmr.10.4.177

https://doi.org/10.18869/nirp.jmr.10.4.177

Article info:

Received: 22 Apr. 2016

Revised: 17 Jun 2016

Accepted: 03 Aug. 2016

\section{Keywords:}

Neurofeedback, Reading skill, Dyslexia

\section{ABSTRACT}

Introduction: Progress in understanding dyslexia has led to the discovery of abnormal brain waves in the areas related to reading skill. It seems that improving the function of these areas by regulating their waves is helpful for reading process. This study aimed to investigate the efficacy of neurofeedback training (NFT) in improving children's reading difficulties.

Material and Methods: This was a single-subject experiment with A-B-A design. Four dyslexic boys (age range 8-12 years) received twenty 30-minute sessions of NFT three times a week to reduce their theta and delta waves at F7 and increase their beta wave at T3. Their accuracy, speed, reading comprehension, and spelling skill were assessed using Name reading test before, during, and one month after treatment. Data analysis was done by reliable change index, mean percentage improvement, and effect size. Also results were displayed by graphs.

Results: The results showed clinically significant improvement regarding the accuracy and comprehension reading as well as spelling after NFT. Reliable changes $(\mathrm{P}<0.05)$ and the effect size above the effective surface (Cohen's $d>2.87$ ) refer to significant improvement of these skills. However speed reading increased in two subjects, but the effect size for the first and second participant was negative (Cohen's $\mathrm{d}<0$ ).

Conclusion: The results suggest that 20 sessions of NFT improves the spelling, accuracy, and comprehension reading. It seems that the increased attention (due to the reduction of theta and delta waves) and performance tuning at T3 was effective in improving these skills. However, increase in speed reading may require more sessions.

* Corresponding Author: 


\section{Introduction}

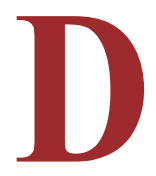

evelopmental dyslexia is a significant disorder prevalently occurs in children with learning disability. This problem characterized with difficulty in learning to read and weakness in spelling that cannot be justified by cognitive deficits, sensory impairment, lack of motivation, or adequate training $[1,2]$. Because of the key role of reading in the learning process, untreated reading and spelling difficulties results in educational and academic failure.

Many researchers consider dyslexia as a disorder with neurological basis and most of them believe that the main problem in these patients relates to a functional impairment in the brain mechanisms for language and particularly in components that are responsible for phonological analysis [3]. Some of these areas include superior temporal gyrus that plays an important role in integration of letters/sounds and inferior frontal lobe which is involved in phonological segmentation and combination [4-8].

Numerous studies have reported anatomical and functional differences in this language network [9]. Neuroimaging studies pointed to functional differences, including increased activity in inferior frontal lobe and lower activity, especially in the temporal lobe as well as weak coordination between inferior frontal lobe and superior temporal gyrus [10]. Difficulties in phonological processing are associated with dysfunction of these areas as a result of structural differences [11-13].

Electroencephalography (EEG) findings also indicate differences in brain function by measuring brain waves in the left hemisphere language areas between children with reading disabilities and normal children. Arns, Peters, Breteler, and Verhoeven [14] reported a significant increase of slow-wave activity (delta and theta) in the frontal and temporal regions in children with dyslexia. Rippon and Brunswick [15] referred to increased level of theta waves in frontal during a phonological processing task compared to normal as well as the lack of increased beta wave in temporal lobe during reading with difficult levels in dyslexic group compared to normal individuals was reported by Norman and Walker [16].

Klimesch, Doppelmayr, Wimmer, Gruber, Röhm, Schwaiger, and Hutzler (2001) [17] reported the ability to process and select words and numbers in specific areas of the brain identified by beta wave activity. They suggested that activity of beta wave indicates integration grapheme-phoneme just in normal group. However in- creased activity of theta wave could be due to low active task engagement. This band wave is also considered as an indicator of verbal working memory acting during cognitive processing in a number of recent studies. Efforts to reduce theta band can be associated with improved cognitive skills [18].

The results of neuropsychological rehabilitation suggest that improvement in behavior may require a direct change in brain function. As a result, these changes appear as positive behavior modification [19]. Therefore, wave training can provide the opportunity beyond the traditional cognitive therapy to improve reading difficulties in this population. Neurofeedback is a non-invasive method that through modification and adjustment of brain waves, works as a new therapeutic tool for enhancing cognitive function in brain-related conditions, such as specific learning disorder (Dyslexia) [20].

According to Thornton and Carmody [10], findings on the efficacy of neurofeedback are insufficient, especially for reading disorder. However, some studies have reported the effectiveness of neurofeedback training to reduce reading errors and improvement in working memory, visual memory, attention and timing of cognitive processes, as essential functions of reading-spelling skills in children with dyslexia [21-25].

A study on 12 children with dyslexia has proved that this method improves comprehension and speed reading, while the use of neurofeedback training by Breteler et al. [26] on dyslexic children showed no improvement in reading ability [16]. Due to inconclusive results of research in this field and the insufficiency of common treatments for dyslexia, more research is required in this field to find better treatments for this group of children. Therefore, this study was conducted to evaluate the effect of neurofeedback training (NFT) on relieving the problems of spelling, accuracy, speed, and comprehension reading.

\section{Materials and Methods}

\section{Participants}

Four male children with dyslexia were recruited from the Learning Disability centers in Tehran. According to these centers medical information, the children had no history of any neurological, emotional disorder and sensory problems such as uncompensated visual impairments and hearing disorders. Reading disorder was confirmed based on reading disability test, teacher reports and normal Intelligent Quotient (IQ) (Wechsler Intelligence Scale for Children-IV). Participants' age ranged 
from 8 to 12 years and all of them were monolingual. The necessary information was provided to children's parents to take their consent forms. Then appropriate information regarding research was explained to children to encourage their participation in the research (Table 1).

\section{Procedure}

The research design was A-B-A single-subject. Before the intervention, speed, accuracy, and comprehension reading and spelling skills of the children were measured 3 times in 3 weeks and the first results were recorded on the baseline (phase A). Then, during the intervention (phase B), each participant received 20 sessions of NFT as the independent variable. Sessions were held three times a week and each session took about 30 minutes. During the sessions, visual feedbacks were used for training after 2 minutes baseline with eye open (as, no feedback offered). At the seventh, $14^{\text {th }}$, and $20^{\text {th }}$ treatment sessions, spelling, accuracy, speed and comprehension reading of the children were measured again to determine their progress. One month after completion of intervention, these variables were measured again in follow-up (phase A).

The training protocol was designed to increase beta wave $(18-15 \mathrm{~Hz})$ at $\mathrm{T} 3$ and reduce theta $(4-8 \mathrm{~Hz})$ and delta (1-4 Hz) waves at F7 according to studies by Walker and Norman, (2006), Rippon and Brunswick (2000), Arns et al. (2007) [14-16]. Each session included 2 minutes baseline and the first 15 minutes of training to increase the beta at T3 then 2 minutes baseline and 15 minutes of training to reduce the delta and theta at F7.

\section{Measurements}

The standard text of name reading test, was used to assess dependent variables of speed, accuracy, and comprehension reading. This standard reading test consists of ten subtests and determines the dyslexia for grades 1 to 5 . Also to check the number of spelling errors used the spelling test in the baseline, during the treatment and post-treatment phase [27]. Measuring brain waves (beta, theta, and delta) in T3, F7 areas and providing feedbacks during treatment sessions done by Nexus-10 neurofeedback hardware system with Bio Trace software. There is no reliable and valid measurement for assessment of spelling at grade 5 in Persian. However, spelling analysis was not done for case 4

\section{Statistical analysis}

According to the case-study design, to determine the statistical relationship, visual analysis of graphs, mean, standard SDs, mean percentage improvement, and reliable change index were calculated for the baseline, treatment, and follow-up sessions, also to view the effect of the treatment, the Cohen guidelines for the $\mathrm{d}$ statistic was used $[15,28]$.

\section{Results}

\section{Reading ability}

Figures 1 shows the participants' performance in three skills of accuracy, speed and reading comprehension during baseline, treatment and follow-up phases of the study. As seen in Figure 1A, reading comprehension in all participants has increased compared to baseline phases following NFT. Progression of speed reading is also observed in the participant 3 and 4, while demonstrates a negative slope for the participant 1 and near 0 in participant 2 according to the Figure 1B. Also, visual analysis of the results revealed that all but one participant displayed an increase in the percentage of correct words during the 20 sessions of NFT relative to the baseline. However, improvement of the accuracy reading in participant 1 had a fluctuating mode. As seen, his scores of accuracy reading declined during the first nine sessions of the treatment but in following sessions, a recovery process was observed and remained well up to a month after the treatment.

Table 1. Participants history

\begin{tabular}{|c|c|c|c|c|c|c|c|}
\hline \multirow[b]{2}{*}{ Participant } & \multirow[b]{2}{*}{ Age, y } & \multirow[b]{2}{*}{ Gender } & \multirow[b]{2}{*}{ Grade } & \multirow{2}{*}{$\begin{array}{c}\text { Intelligence } \\
\text { Quotient }\end{array}$} & \multicolumn{3}{|c|}{ History of } \\
\hline & & & & & $\begin{array}{c}\text { Neurological } \\
\text { Problems }\end{array}$ & $\begin{array}{l}\text { Emotional } \\
\text { Disorders }\end{array}$ & $\begin{array}{l}\text { Sensory } \\
\text { Problem }\end{array}$ \\
\hline Case 1 & 8 & Male & Second & Normal (95) & - & - & - \\
\hline Case 2 & 8 & Male & Second & Normal (100) & - & - & - \\
\hline Case 3 & 9 & Male & Third & Normal (100) & - & - & - \\
\hline Case 4 & 11 & Male & Fifth & Normal (105) & - & - & - \\
\hline
\end{tabular}


The result of significant clinical changes methods also implies the effectiveness of NFT on reading comprehension. So that the effect size by using Cohen's d was calculated between 4.09 and 8.09 for this variable; considering large effect size in single case studies (2.87), this range (4.09 to 8.09) reveals the high rate of change and improvement. The effect size obtained for the speed reading in participants 1 and 2 (9.38 and 6.40) was significant but the effect size for the first and second participants was negative.
For accuracy of reading, the effect size was calculated from 2.20 to 6.61; participant 1 had the lowest level of effectiveness. Tables 2, 3 and 4 present that mean, SD, MPI, RCI, and Cohen's d value for speed, comprehension, and accuracy reading in all participants. The participants increased their reading comprehension skill in magnitude from $24.60 \%$ to $49.05 \%$, and maximum of improvement for speed reading was $49.39 \%$. The minimum and maximum improvements in accuracy reading were found to be 5.65\% and $23.48 \%$, respectively. The percentage of improvement

A

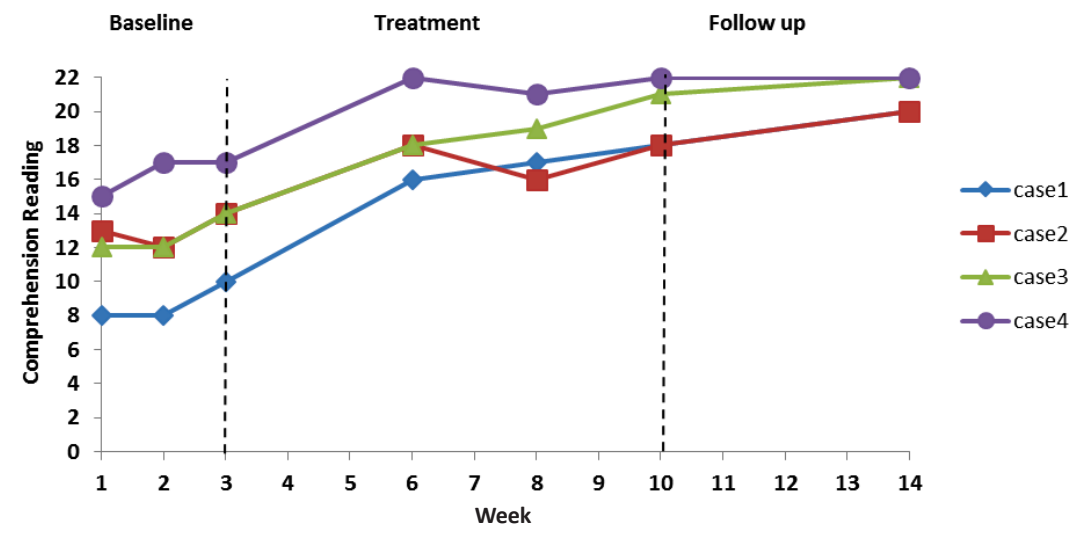

B

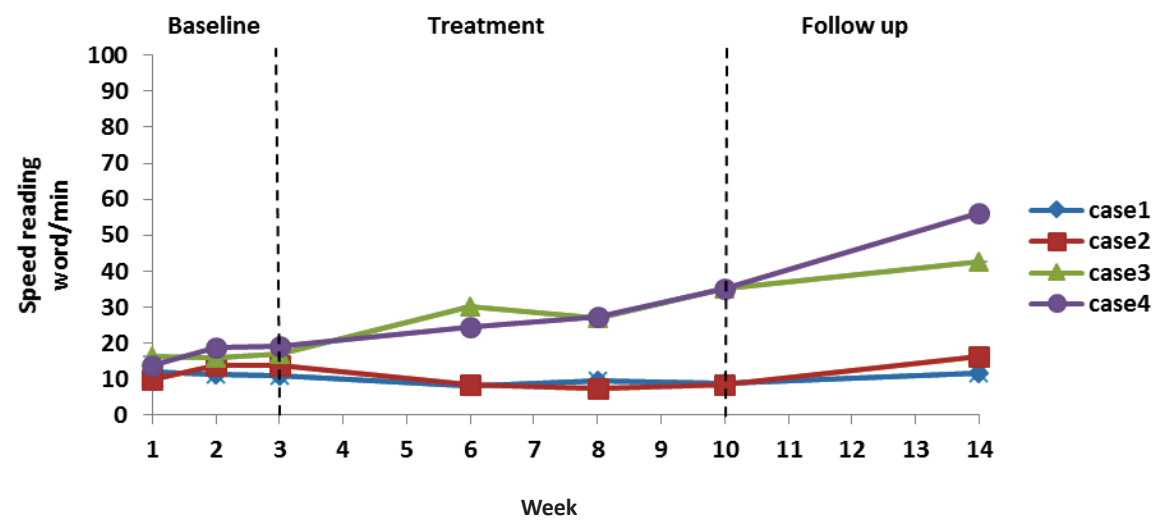

C

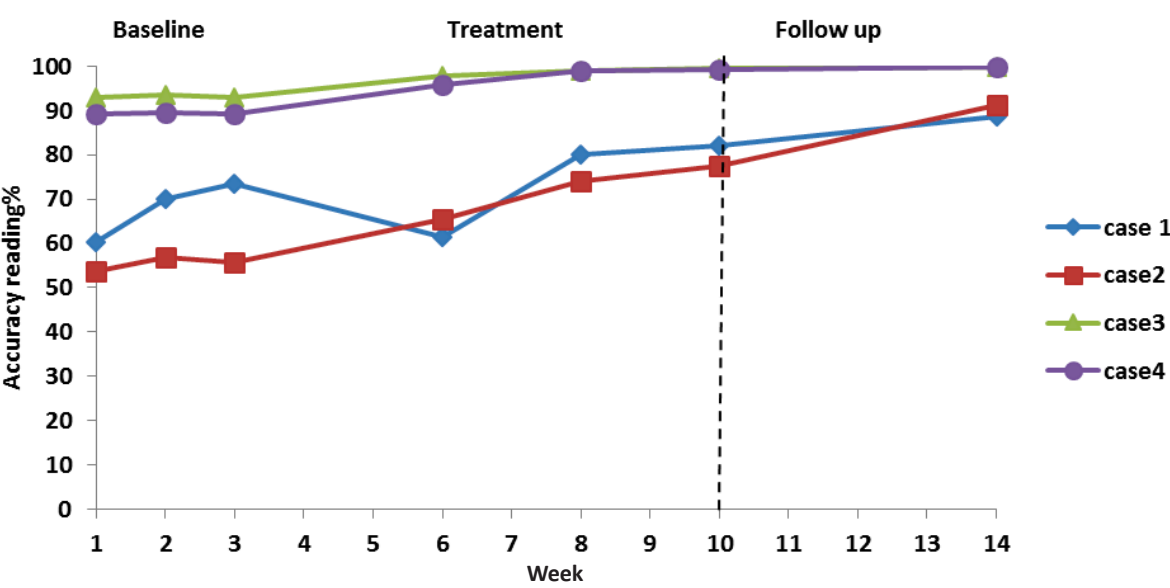

Figure 1. Pattern of reading ability changes across baseline, treatment, 1-month follow-up assessments 
Table 2. Scores of participants on comprehension reading skill at baseline, treatment, 1-month follow-up assessments

\begin{tabular}{cccccccccc}
\hline & Mean $\mathbf{A}_{1}$ & Mean B & Mean $\mathbf{A}_{2}$ & SD.A $_{1}$ & SD.B & $\begin{array}{c}\text { Cohen's } d \\
\mathbf{A}_{1}-\mathbf{B}\end{array}$ & $\begin{array}{c}\text { RCI } \\
\mathbf{A}_{2}-\mathbf{A}_{1}\left(\mathbf{B}-\mathbf{A}_{1}\right)\end{array}$ & $\begin{array}{c}\text { MPI } \\
\mathbf{A}_{1}-\mathbf{A}_{2}\end{array}$ & $\begin{array}{c}\text { MPI } \\
\mathbf{A}_{1}-\mathbf{B}\end{array}$ \\
\hline Case1 & 8.66 & 17 & 20 & 1.15 & 1 & 8.09 & $9.07(11.12)$ & $56.70 \%$ & $49.05 \%$ \\
Case2 & 13 & 18 & 20 & 1 & 2 & 4.09 & $5.60(6.66)$ & $35 \%$ & $27.77 \%$ \\
Case3 & 12.66 & 19.33 & 22 & 1.15 & 1.52 & 5.80 & $7.47(8.89)$ & $42.45 \%$ & $34.50 \%$ \\
Case4 & 16.33 & 21.66 & 22 & 1.15 & 0.57 & 5.79 & $4.53(7.10)$ & $25.72 \%$ & $24.60 \%$ \\
\hline
\end{tabular}

Abbreviations: A1: baseline phase; B: treatment phase; A2: follow-up; SD: Standard Deviation; MPI: Mean Percentage Improvement; RCI: Reliable change index

in baseline compared to follow-up phase implies an increasing trend for all participants in reading variables.

\section{Spelling}

Figure 2 demonstrates performance of participants on spelling skill during baseline, treatment, and follow-up phases. According to the graph, increasing trend and positive slope for all participants can be seen in spelling. The scores of spelling skill in all participants after NFT according to reliable change index (1.96 equates to the $95 \%$ confidence interval) were statistically significant and reliable. Comparison of baseline treatment phases based on effect size (Cohen's d) also demonstrates significant progress with a maximum of 5.66 and minimum of 3.27. The mean percentage of improvement ranged from 21.05 to 200 indicates that the level of word spelling mistakes is reduced in all participants (Table 5).

\section{Discussion}

All participants showed significant improvement in accuracy and reading comprehension as well as spelling during 20 sessions of NFT. In other words, the findings of this study by using clinical significance methods show that NFT can improve reading skills of individuals with dyslexia. This result is in line with Norman and Walker [16] study done on 12 children with dyslexia. They reported that increase in beta wave at T3 can improve the reading comprehension.

Thornton and Carmody [10] mentioned that a subject earned a standard score in the reading comprehension test after 20 sessions and the other subject after 40 sessions of NFT. The results can be explained by considering the biological basis of dyslexia. Dysfunction of brain waves in areas related to reading (like temporal gyrus and inferior frontal areas in dyslexic children) is blamed for reading problems [14-16]. Because the superior temporal gyrus plays a role in word comprehension (phonemic composition, semantic and lexical representation), semantic processing, also integrating visual, auditory, perceptual and memory inputs to provide fluent reading, tuning beta wave in this area improves its performance and consequently may enhance reading comprehension [16].

Costanzo, Menghini, Caltagirone, Oliveri, and Vicari [29] found that the left superior temporal gyrus stimula-

Table 3. Scores of participants on speed reading skill at baseline, treatment, 1-month follow-up assessments

\begin{tabular}{cccccccccc}
\hline & Mean A $_{1}$ & Mean B & Mean $\mathbf{A}_{2}$ & SD.A $_{1}$ & SD.B & $\begin{array}{c}\text { Cohen's } \\
d \mathbf{A}_{1}-\mathbf{B}\end{array}$ & $\begin{array}{c}\text { RCI } \\
\mathbf{A}_{2}-\mathbf{A}_{1}\left(\mathbf{B}-\mathbf{A}_{1}\right)\end{array}$ & $\begin{array}{c}\text { MPI } \\
\mathbf{A}_{1}-\mathbf{A}_{2}\end{array}$ & $\begin{array}{c}\text { MPI } \\
\mathbf{A}_{1}-\mathbf{B}\end{array}$ \\
\hline Case1 & 11.46 & 8.8 & 11.76 & 0.66 & 0.65 & -3.25 & $0.03(-0.55)$ & $2.55 \%$ & $-30.22 \%$ \\
Case2 & 12.48 & 8.16 & 16.47 & 2.09 & 0.55 & -3.79 & $0.43(-0.90)$ & $24.22 \%$ & $-52.94 \%$ \\
Case3 & 16.49 & 30.76 & 42.69 & 0.51 & 4.13 & 9.38 & $2.85(2.97)$ & $61.37 \%$ & $49.39 \%$ \\
Case4 & 17.29 & 28.95 & 56.26 & 3.05 & 5.45 & 6.04 & $4.24(2.43)$ & $65.76 \%$ & $40.27 \%$ \\
\hline
\end{tabular}


Table 4. Scores of participants on accuracy reading skill at baseline, treatment, 1-month follow-up assessments

\begin{tabular}{cccccccccc}
\hline & Mean $\mathbf{A}_{1}$ & Mean B & Mean $\mathbf{A}_{2}$ & SD.A & SD.B & $\begin{array}{c}\text { Cohen's } d \\
\mathbf{A}_{1}-\mathbf{B}\end{array}$ & $\begin{array}{c}\text { RCI } \\
\mathbf{A}_{2}-\mathbf{A}_{1}\left(\mathbf{B}-\mathbf{A}_{1}\right)\end{array}$ & $\begin{array}{c}\text { MPI } \\
\mathbf{A}_{1}-\mathbf{A}_{2}\end{array}$ & $\begin{array}{c}\text { MPI } \\
\mathbf{A}_{1}-\mathbf{B}\end{array}$ \\
\hline Case1 & 67.98 & 74.60 & 88.74 & 6.89 & 11.32 & 2.20 & $3.18(2.55)$ & $23.39 \%$ & $8.87 \%$ \\
\hline Case2 & 55.40 & 72.40 & 91.39 & 1.66 & 6.15 & 8.62 & $5.52(6.56)$ & $39.38 \%$ & $23.48 \%$ \\
Case3 & 93.15 & 98.73 & 100 & 0.31 & 0.82 & 7.44 & $1.05(2.15)$ & $6.85 \%$ & $5.65 \%$ \\
Case4 & 89.42 & 98.09 & 100 & 0.16 & 1.86 & 6.61 & $1.62(3.34)$ & $10.58 \%$ & $8.83 \%$ \\
\hline
\end{tabular}

$J \mathrm{MR}$

Abbreviations: A1, Baseline phase; B, Treatment phase; A2, Follow-up; SD, Standard Deviation; MPI, Mean PercentageImprovement; RCI, Reliable change index

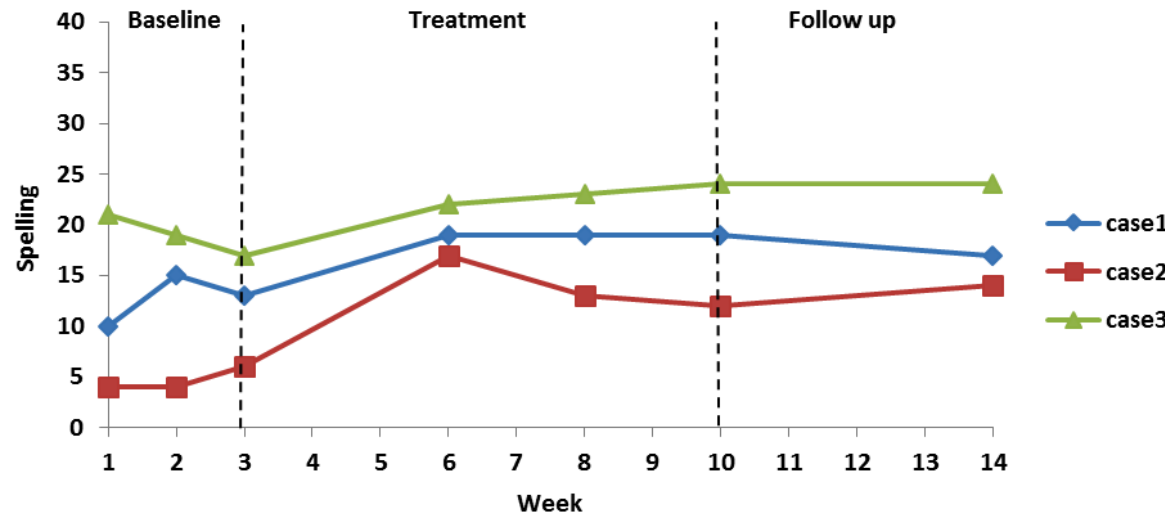

Figure 2. Pattern of spelling changes across baseline, treatment, 1-month follow-up assessments

tion improved the text reading accuracy. As a result, increase in beta waves in the temporal region can also improve the reading accuracy as a cognitive task requires attention. Finally improving the reading accuracy will lead to progress in reading comprehension.

Several studies have reported that differences in theta waves (dyslexic in comparison with control) can be considered as an indicator of attentional dysfunction underpinning reading difficulties, also high levels of theta wave considered as evidence of less active task engagement $[15,30]$.

Thus reducing this wave could lead to improvement in cognitive skills (such as attention). Mann, Lubar, Zimmerman, Miller, and Muenchen [31] reported that in children with diagnosis of attention deficit, adjustment of beta and theta waves improves attention deficit. Thus increasing beta and reducing low waves such as theta, delta help rising attention and could have a significant

Table 5. Scores of participants on spelling skill at baseline, treatment, 1-month follow-up assessments

\begin{tabular}{cccccccccc}
\hline & Mean $\mathbf{A}_{1}$ & Mean B & Mean $\mathbf{A}_{2}$ & SD.A & SD.B & $\begin{array}{c}\text { Cohen's } d \\
\mathbf{A}_{1}-\mathbf{B}\end{array}$ & $\begin{array}{c}\text { RCI } \\
\mathbf{A}_{2}-\mathbf{A}_{1}\left(\mathbf{B}-\mathbf{A}_{1}\right)\end{array}$ & $\begin{array}{c}\text { MPI } \\
\mathbf{A}_{1}-\mathbf{A}_{2}\end{array}$ & $\begin{array}{c}\text { MPI } \\
\mathbf{A}_{1}-\mathbf{B}\end{array}$ \\
\hline Case1 & 12.66 & 19 & 17 & 2.51 & 0 & 5.66 & 4.1 & $50.07 \%$ & $34.28 \%$ \\
Case2 & 4.66 & 14 & 14 & 1.15 & 2.64 & 6.81 & 6.06 & $200 \%$ & $200 \%$ \\
Case3 & 19 & 23 & 24 & 2 & 1 & 3.27 & 2.59 & $21.05 \%$ & $26.31 \%$ \\
\hline
\end{tabular}

Abbreviations: A1, Baseline phase; B, Treatment phase; A2, Follow-up; SD, Standard deviation; MPI, Mean percentage improvement; RCI, Reliable change index 
role in reading accuracy. The inferior frontal gyrus plays a role in phonological processing and verbal working memory as potential factors in reading. Thus improving the performance of this area through adjusting the waves may be the reason to enhance reading accuracy $[32,33]$.

Orlando and Rivera [34] also reported increased reading accuracy as a result of NFT similar to our study but Breteler et al. [26] observed no significant improvement in the reading ability in dyslexic children after 20 sessions of NFT [34]. NFT no improve speed reading in two participants, due to the low scores in reading accuracy pretest could be noted that trying to increase accuracy of reading with more attention to content cause reading speed was decreased [7]. La Marca [35] mentioned that most participants did not read faster after 40 sessions NFT but their reading accuracy improved. So, it demonstrates that the intervention help participants to read with more attention to the content.

The results also indicated that the intervention mainly affects spelling. Referring to the under activation superior temporal gyrus in dyslexic for mapping auditory phonemes onto visual graphemes can cause difficulty in spelling [36]. Boosting the performance of this area might be an explanation for improved spelling. However, the increased attention (due to the reduction of theta and delta waves) also has an important role in reducing spelling errors. Breteler et al. also proposed that attentional processes are involved in improving spelling in individuals with dyslexia [26].

Findings of this research support positive effect of NFT on spelling and reading skills (including accuracy and comprehension reading) in children with dyslexia. It seems that adjusting the function of the frontal and temporal areas leads to positive changes in reading. Also increase in cognitive skills such as attention following the reduction of slow wave in frontal lobe is associated with reducing errors in spelling and reading. These findings suggest that changes in behavior are a reflection of changes in the brain function. Therefore, the results confirmed the effectiveness of NFT on improving reading and spelling problems in children with dyslexia. The caution in generalization of these results is warranted with respect to small sample size; however, it is suggested that further research with larger sample size and control group be conducted.

\section{Acknowledgments}

This research was carried out at Rehabilitation Faculty Neurofeedback Lab and was Financialy supported by Tehran University of Medical Sciences.

\section{Conflict of Interest}

The authors declared no conflicts of interest.

\section{References}

[1] Ferrer E, Shaywitz BA, Holahan JM, Marchione K, Shaywitz SE. (2010). Uncoupling of reading and IQ over time empirical evidence for a definition of dyslexia. Psychological science, 21(1), 93-101.

[2] Shaywitz SE. Dyslexia. New England Journal of Medicine 1998; 338(5):307-12. doi: 10.1056/nejm199801293380507

[3] Simos PG, Fletcher JM, Bergman E, Breier JI, Foorman BR Castillo EM, et al. Dyslexia-specific brain activation profile becomes normal following successful remedial training. Neurology. 2002; 58(8):1203-13. doi: 10.1212/wnl.58.8.1203

[4] Burton MW, Small SL, Blumstein SE. The role of segmentation in phonological processing: An FMRI investigation Journal of Cognitive Neuroscience. 2000; 12(4):679-90. doi 10.1162/089892900562309

[5] Burton M. The role of inferior frontal cortex in phonological processing. Cognitive Science. 2001; 25(5):695-709. doi: 10.1016/s0364-0213(01)00051-9

[6] Jobard G, Vigneau M, Mazoyer B, Tzourio-Mazoyer N. Impact of modality and linguistic complexity during reading and listening tasks. NeuroImage. 2007; 34(2):784-800. doi: 10.1016/j.neuroimage.2006.06.067

[7] Vellutino FR, Fletcher JM, Snowling MJ, Scanlon DM. Specific reading disability (dyslexia): What have we learned in the past four decades? Journal of Child Psychology and Psychiatry. 2004; 45(1):2-40. doi: 10.1046/j.0021-9630.2003.00305.x

[8] Zatorre R, Evans A, Meyer E, Gjedde A. Lateralization of phonetic and pitch discrimination in speech processing. Science. 1992; 256(5058):846-9. doi: 10.1126/science.1589767

[9] Snowling MJ. Phonemic deficits in developmental dyslexia. Psychological Research 1981; 43(2):219-34. doi: 10.1007/ bf00309831

[10] Thornton KE, Carmody DP. Electroencephalogram biofeedback for reading disability and traumatic brain injury. Child and Adolescent Psychiatric Clinics of North America 2005; 14(1):137-62. doi: 10.1016/j.chc.2004.07.001

[11] Brown WE, Eliez S, Menon V, Rumsey JM, White CD, Reiss AL. Preliminary evidence of widespread morphological variations of the brain in dyslexia. Neurology. 2001; 56(6):781-3. doi: 10.1212/wnl.56.6.781

[12] Foster LM., Hynd GW, Morgan AE, Hugdahl K. P Planum temporale asymmetry and ear advantage in dichotic listening in developmental dyslexia and Attention-Deficit/ Hyperactivity Disorder (ADHD). Journal of the International Neuropsychological Society. 2002; 8(1):22-36. doi: 10.1017/ s1355617701020033

[13] Pennington BF, Filipek PA, Lefly D, Churchwell J, Kennedy $\mathrm{DN}$, Simon JH, et al. Brain morphometry in reading- 
disabled twins. Neurology. 1999; 53(4):723-723. doi: 10.1212/ wnl.53.4.723

[14] Arns M, Peters S, Breteler R, Verhoeven L. Different brain activation patterns in dyslexic children: Evidence from eeg power and coherence patterns for the double-deficit theory of dyslexia. Journal of Integrative Neuroscience 2007; 06(01):175-90. doi: 10.1142/s0219635207001404

[15] Rippon G, Brunswick N. Trait and state EEG indices of information processing in developmental dyslexia. International Journal of Psychophysiology. 2000; 36(3):251-65. doi: 10.1016/s0167-8760(00)00075-1

[16] Walker JE, Norman CA. Theneurophysiology of dyslexia: a selective review with implications for neurofeedback remediation and results of treatment in twelve consecutive patients. Journal of Neurotherapy. 2006; 10(1):45-55. doi: 10.1300/ j184v10n01_04

[17] Klimesch W, Doppelmayr M, Wimmer H, Gruber W, Röhm D, Schwaiger J, et al. Alpha and beta band power changes in normal and dyslexic children. Clinical Neurophysiology. 2001; 112(7):1186-95. doi: 10.1016/s1388-2457(01)00543-0

[18] Orekhova EV, Stroganova TA, Posikera IN. Theta synchronization during sustained anticipatory attention in infants over the second half of the first year of life. International Journal of Psychophysiology. 1999, 32(2):151-172. doi: 10.1016/ s0167-8760(99)00011-2

[19] Stuss DT. The future of cognitive neurorehabilitation. Neuropsychological Rehabilitation. 2011; 21(5):755-68. doi: 10.1080/09602011.2011.605590

[20] Hammond DC. What is neurofeedback: An update. Journal of Neurotherapy. 2011; 15(4):305-36. doi: 10.1080/10874208.2011.623090

[21] Au A, Ho GSM, Choi EWM, Leung P, Waye MMY, Kang $\mathrm{K}$, et al. Does it help to train attention in dyslexic children: pilot case studies with a ten-session neurofeedback program. International Journal on Disability and Human Development. 2013; 13(1):1-10. doi: 10.1515/ijdhd-2013-0005

[22] Ghaemi H, Toozandehjani H. The effectiveness of neurofeedback on working memory, visual memory and reading ability in children with Dyslexia. Journal of Current Research in Science. 2016; 2:870-75.

[23] Mosanezhad-Jeddi E, Nazari, MA. Effectiveness of EEGbiofeedback on attentiveness, working memory and quantitative electroencephalography on reading disorder. Iranian Journal of Psychiatry and Behavioral Sciences. 2013; 7(2):3543.

[24] Narimani M, Rajabi S, Abolghasemi A, Nazarei MA, Zahed-Babelan A. [Evaluating the effectiveness of neurofeedback on brain waves and the amplitude correction attention of students with dyslexia (Persian)]. Research in Clinical Psychology and Counseling. 2012; 2(1):5-24. doi: 10.22067/ijap. v2i1.8269

[25] Sadeghi N, Nazari MA. Effect of neurofeedback on visualspatial attention in male children with reading disabilities: An event-related potential study. Neuroscience \& Medicine. 2015; 6(2):71-9. doi: 10.4236/nm.2015.62013

[26] Breteler MHM, Arns M, Peters S, Giepmans I, Verhoeven L. Improvements in spelling after QEEG-based neurofeedback in dyslexia: A randomized controlled treatment study.
Applied Psychophysiology and Biofeedback. 2009; 35(1):511. doi: $10.1007 /$ s10484-009-9105-2

[27] Karmi Nouri R, Moradi A. [Reading \& dyslexia test (Persian)]. Tehran: Jahad-e- Daneshgahi; 2002.

[28] Matthew K, Burns T, Riley-Tillman C. Evaluating educational interventions: Single-case design for measuring response to intervention. New York: Guilford Press; 2011.

[29] Costanzo F, Menghini D, Caltagirone C, Oliveri M, Vicari S. How to improve reading skills in dyslexics: The effect of high frequency rTMS. Neuropsychologia. 2013; 51(14):29539. doi: 10.1016/j.neuropsychologia.2013.10.018.

[30] Ackerman PT, Dykman RA, Oglesby D M, Newton, JE. EEG power spectra of dysphonetic and nondysphonetic poor readers. Brain and language. 1995; 49(2):140-52. doi: 10.1006/ brln.1995.1025

[31] Mann CA, Lubar JF, Zimmerman AW, Miller CA, Muenchen RA. Quantitative analysis of EEG in boys with attention-deficit-hyperactivity disorder: Controlled study with clinical implications. Pediatric Neurology. 1992; 8(1):30-6. doi: 10.1016/0887-8994(92)90049-5

[32] Brady SA. The role of working memory in reading disability. Haskins Laboratories Status Report on Speech Research. 1991; SR-105/106, 9-22.

[33] Trans Cranial Technologies. Cortical function. Wanchai, Hong Kong: Cranial Technologies Ltd; 2012.

[34] Orlando PC, Rivera RO. Neurofeedback for elementary students with identified learning problems. Journal of Neurotherapy. 2004; 8(2):5-19. doi: 10.1300/j184v08n02_02

[35] La Marca JP. Neurofeedback as an intervention to improve reading achievement in students with attention deficit hyperactivity disorder, inattentive subtype [PhD thesis]. California: University of California; 2014.

[36] Leonard CM, Voeller KKS, Lombardino LJ, Morris MK, Hynd GW, Alexander AW, et al. Anomalous cerebral structure in dyslexia revealed with magnetic resonance imaging. Archives of Neurology. 1993; 50(5):461-9. doi: 10.1001/archneur.1993.00540050013008 